\title{
Molecular characterization of Trypanosoma evansi, T. vivax and T. congolense in camels (Camelus dromedarius) of KSA
}

\author{
Jamila S. Al Malki®D and Nahed Ahmed Hussien* ${ }^{*}$
}

\begin{abstract}
Background: Trypanosoma evansi is the leading infectious Trypanosoma spp. in camels (Camelus dromedarius) present in the Kingdom of Saudi Arabia (KSA) that could lead to extensive economic losses. The present study was aimed to assess the prevalence rate of T. evansi in Taif governorate, Makkah province, KSA using parasitological and molecular evaluations, and analyze their genetic relationship targeting internal transcribed spacer 1 (ITS1) and variable surface glycoprotein (VSG) genes. For evaluation, we have used 102 blood samples of camels obtained from three different regions in Taif.

Results: Results show a considerable prevalence rate of trypanosomosis 2/102 (2.0\%) according to Giemsa-stained buffy coat smear, and 16/102 (15.7\%) according to touchdown PCR. T. evansi $(n=10 / 102,9.8 \%)$ was the main infectious species found in camels then T. vivax $(n=3 / 102,2.9 \%)$. Mixed infections were detected in three camels with $T$. evansi, T. vivax, and T. congolense $(n=3 / 102,2.9 \%)$. Regarding gender, the results indicate that female camels $(11 / 66$, 16.7\%) show higher prevalence of Trypanosoma than males (5/36, 13.9\%). Sequencing and phylogenetic analyses of ITS1 and VSG showed their relationships with T. evansi in other hosts from different countries.
\end{abstract}

Conclusions: In our peer knowledge, it is the first time to report a research-based prevalence of trypanosomosis in the camels of Taif governorate, Makkah province, KSA.

Keywords: Trypanosomosis, ITS1, Rotat 1.2 VSG, Phylogeny, Taif governorate, KSA

\section{Background}

Saudi Arabian camels are mainly of the type one-humped (dromedaries, Camelus dromedarius), representing a significant and integral component of the Kingdom heritage. According to the FAO 2019, the Kingdom of Saudi Arabia (KSA) has about $34 \%(492,853)$ of the total population of dromedary present in the Arabian Peninsula (estimated 1.46 million) [1]. Camel population in KSA represents about $51 \%$ of the total tropical livestock unit that increased since 1961 (first available world annual data) [2]. Camels have particular importance in KSA;

*Correspondence: n.nahed@tu.edu.sa; nahed199@gmail.com Department of Biology, College of Science, Taif University, P.O. Box 11099, Taif 21944, Saudi Arabia they are reared for their milk, wool, leather, and meat, in addition to their contribution in racing and cultural festivals, but rarely used for transportation [3].

Trypanosoma evansi (T. evansi) is a protozoan parasite that infects different animals, including horses, donkeys, and dogs [4, 5], camels, sheep, and goats [6], and a potential human pathogen. It causes trypanosomosis that represents a significant threat to an animal's life $[7,8]$. Trypanosoma evansi has a complex and multiple means of transmission that depends on animal host species, biting/sucking insects, geographical area, and mode of transmission, leading to its epidemiological significance in different parts of the world [9].

Camel represents the main host of T. evansi in Middle Asia and certain parts of Africa such as West Africa, 
Sudan, Kenya, and Somalia [10]. Trypanosomosis is present in acute and chronic forms, with different symptoms including fever, anemia, edema, bodyweight loss, lacrimation, conjunctival petechiae, abortion, enlarged lymph nodes, decreased fertility, and could lead to death [11].

There is a scarcity of studies reporting the prevalence of trypanosomosis in different KSA governorates. However, $\mathrm{Al}$-Qassim and Riyadh provinces are the most interesting regions for studying trypanosomosis in KSA [12]. Few studies suggested that tick Hyalomma dromedarii and tabanid flies could be vectors for camel trypanosomosis in KSA. However, they have found Trypanosoma developmental stages in Hyalomma dromedarii salivary glands during their examination. Moreover, they have observed many tabanid flies feeding on camels in the regions where camels showed T. evansi infection, a mechanical vector $[13,14]$.

The present study evaluated the prevalence of camel trypanosomosis, especially T. evansi, in Taif governorate, Makkah province, KSA using parasitological and molecular methods. In addition, the present study assessed the genetic relationship between internal transcribed spacer 1 (ITS-1) and RoTat 1.2 variable surface glycoprotein
(VSG) Taif isolates with other isolates present in other countries in Genbank.

\section{Results \\ Buffy coat examination}

Parasitological examination, using Giemsa stain, in the whole blood smear of all samples $(n=102)$ showed negative results. However, Giemsa staining of buffy coat smear showed positive T. evansi with long terminal free flagella in only two samples (1 male and 1 female, $2.0 \%$ ) (Fig. 1, Table 1). Most of them appeared deformed/lysed in the same two samples (Data not shown). In addition, Fig. 1 showed apoptosis of white blood cell due to trypanosomosis.

\section{Touchdown PCR}

PCR was done to detect Trypanosoma spp. by targeting internal transcribed spacer (ITS) of nuclear ribosomal DNA (rDNA), ITS1, and RoTat 1.2 variable surface glycoprotein (VSG). Touchdown PCR is a good solution for us because we failed to obtain a good amplicon product using conventional PCR with one fixed annealing temperature.
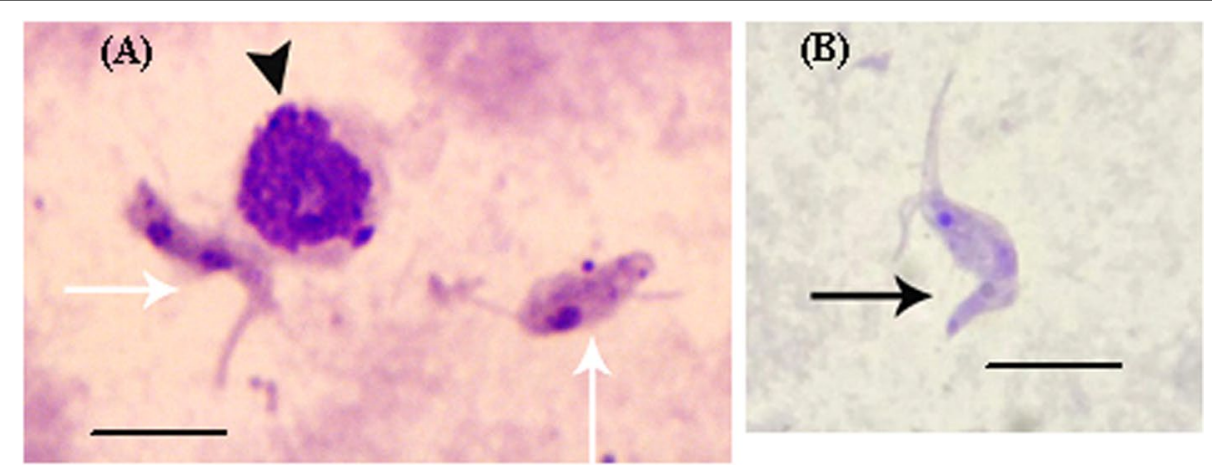

Fig. 1 Light micrographs of camels' blood buffy coat smear showing Giemsa-stained Trypanosoma evansi with long terminal free flagella (white (A) and black arrows (B)) and apoptotic lymphocyte (black arrowhead, (A)). Scale-bars: $10 \mu \mathrm{m}$

Table 1 Prevalence of trypanosomosis according to parasitological and molecular assays

\begin{tabular}{lllll}
\hline Gender & Number $(n) /$ Age & $\begin{array}{l}\text { Buffy coat parasitological } \\
\text { detection }\end{array}$ & PCR detection & $\begin{array}{l}\text { Trypanosoma spp. } \\
\text { detected by PCR } \\
\text { detected }\end{array}$ \\
\hline Female & $n=66$ & $1 / 66(1.5 \%)$ & $11 / 66(16.7 \%)^{* * *}$ & $\begin{array}{l}\text { T.evansi=10/102 (9.8\%)*** } \\
\text { T. vivax }=3 / 102(2.9 \%) \\
\text { a.Mixed }=3 / 102(2.9 \%)\end{array}$ \\
Male & Age (3-12yrs) & $1 / 36(2.8 \%)$ & $5 / 36(13.9 \%)$ & $16 / 102(15.7 \%)$ \\
Total & $\begin{array}{l}n=36 \\
\text { Age (1-7yrs) }\end{array}$ & $2 / 102(2.0 \%)$ & $16 / 102(15.7 \%)$ & \\
\hline
\end{tabular}

Detection of Trypanosoma spp. in blood of camels

In which, ${ }^{* * *}$ indicates $P \leq 0.001$ comparing related samples with each other

${ }^{a}$ Mixed infection of T. evansi and vivax was detected by Kin primers, while mixed infection of T. evansi, vivax, and congolense was detected by ITS1 primers 

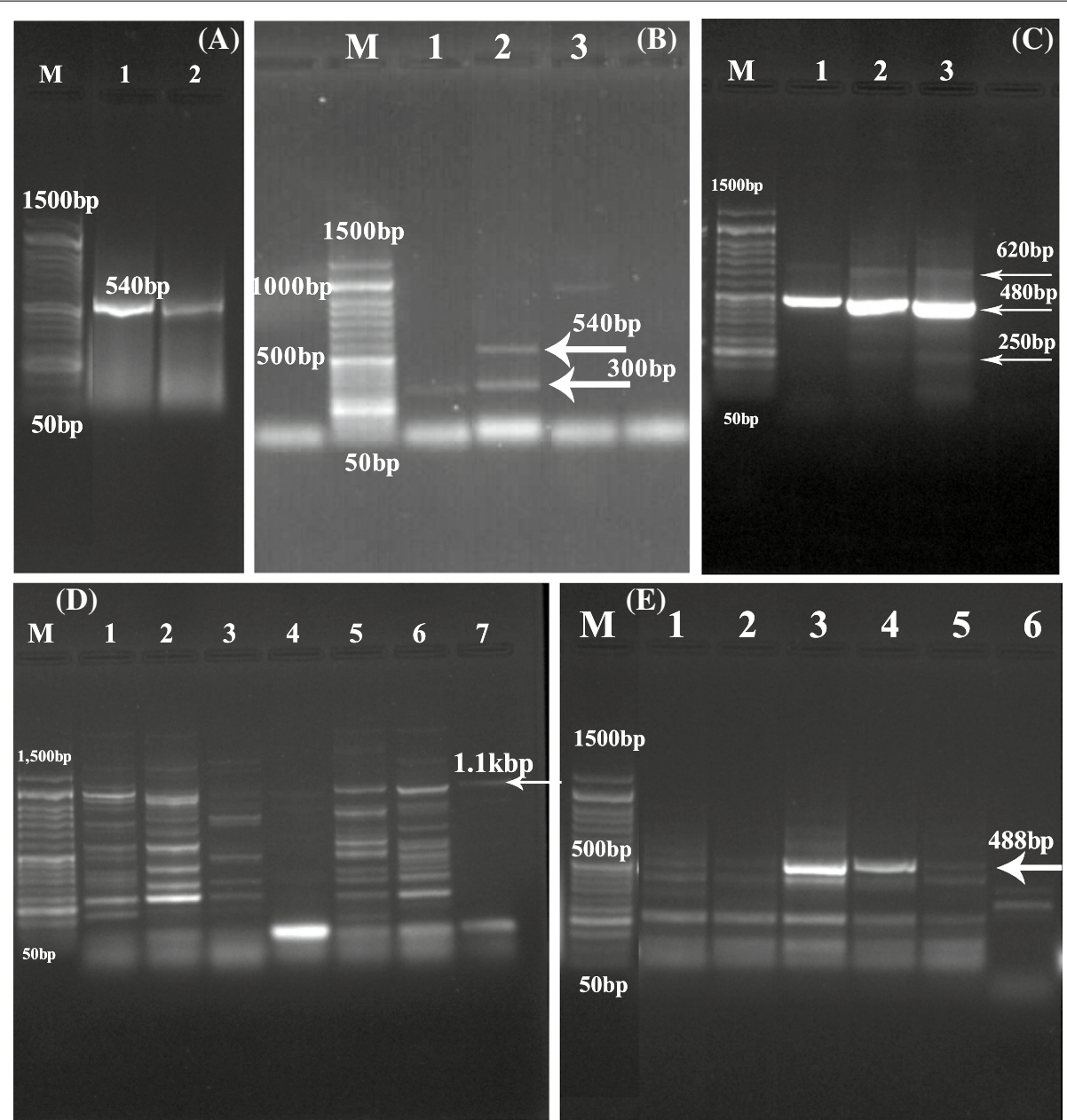

Fig. 2 Agarose gel stained with ethidium bromide (1.5\%) showing PCR product of ITS1 using Kin primers (A and B). Gel (A) Lanes 1,2: Trypanosoma evansi (540 bp), Gel (B) Lane 1: T. vivax (300 bp), and Lane 2: Mixed infection of T. evansi and T. vivax. Gel (C) showing PCR product of ITS1 using ITS1 primers; Lanes 1, 2, 3: Mixed infection of Trypanosoma evansi (480 bp), T. vivax (250 bp), and T. congolense (620 bp). Gel (D) showing PCR product of ITS using IR primers; Lanes 1-7: Trypanosoma evansi (1.1 kbp). Gel (E) showing PCR product of Rotat 1.2 VSG region using ILO primers; Lanes 1-6: Trypanosoma evansi (488 bp). Any other lower and higher bands are non-specific. Lane M: Low molecular weight marker (50-1500 bp)

PCR results revealed infection of 16 camels (15.7\%) with Trypanosoma spp. Females have a significant infection rate higher $(16.7 \%)$ than males $(13.9 \%)$ at $P \leq 0.001$ (Table 1). PCR results using Kin primers that targeted ITS1 showed 16 positive samples, in which 10 samples have PCR product at $540 \mathrm{bp}, 3$ samples with $300 \mathrm{bp}$, and 3 samples mixed between $540 \mathrm{bp}$ and $300 \mathrm{bp}$ that referred to $T$. evansi, T. vivax, and mixed infection of both $T$. evansi and T. vivax, respectively (Fig. 2A, B).

Using ITS primers that targeted ITS1 region reported ten samples with $T$. evansi infection $(480 \mathrm{bp})$ and three mixed infection samples of T. evansi (480 bp), T. vivax (250 bp), and T. congolense (620 bp) (Fig. 2C). At the same time, IR primers were used to amplify ITS region $(\mathrm{ITS} 1+5.8 \mathrm{~S}+\mathrm{ITS} 2 \mathrm{rDNA})$ of $T$. evansi that detected ten samples with a main $1.1 \mathrm{kbp}$ band and other non-specific bands (Fig. 2D). Rotat 1.2 VSG region for T. evansi was detected in 10 samples using ILO primers with amplicon size $488 \mathrm{bp}$, while other lower and higher bands are non-specific (Fig. 2E). Therefore, T. evansi $(n=10 / 102$, $9.8 \%$ ) has been significantly reported at $P \leq 0.001$ by PCR in comparison to $T$. vivax $(n=3 / 102,2.9 \%)$, and then mixed infections $T$. evansi, $T$. vivax, and $T$. congolense $(n=3 / 102,2.9 \%)$ as mentioned in Table 1.

\section{Sequencing and phylogeny}

Since T. evansi is the most common infectious species in Taif camels than T. vivax and T. congolense, we randomly selected about twelve different $T$. evansi PCR products samples using Kin (540 bp), ITS (480 bp), and 


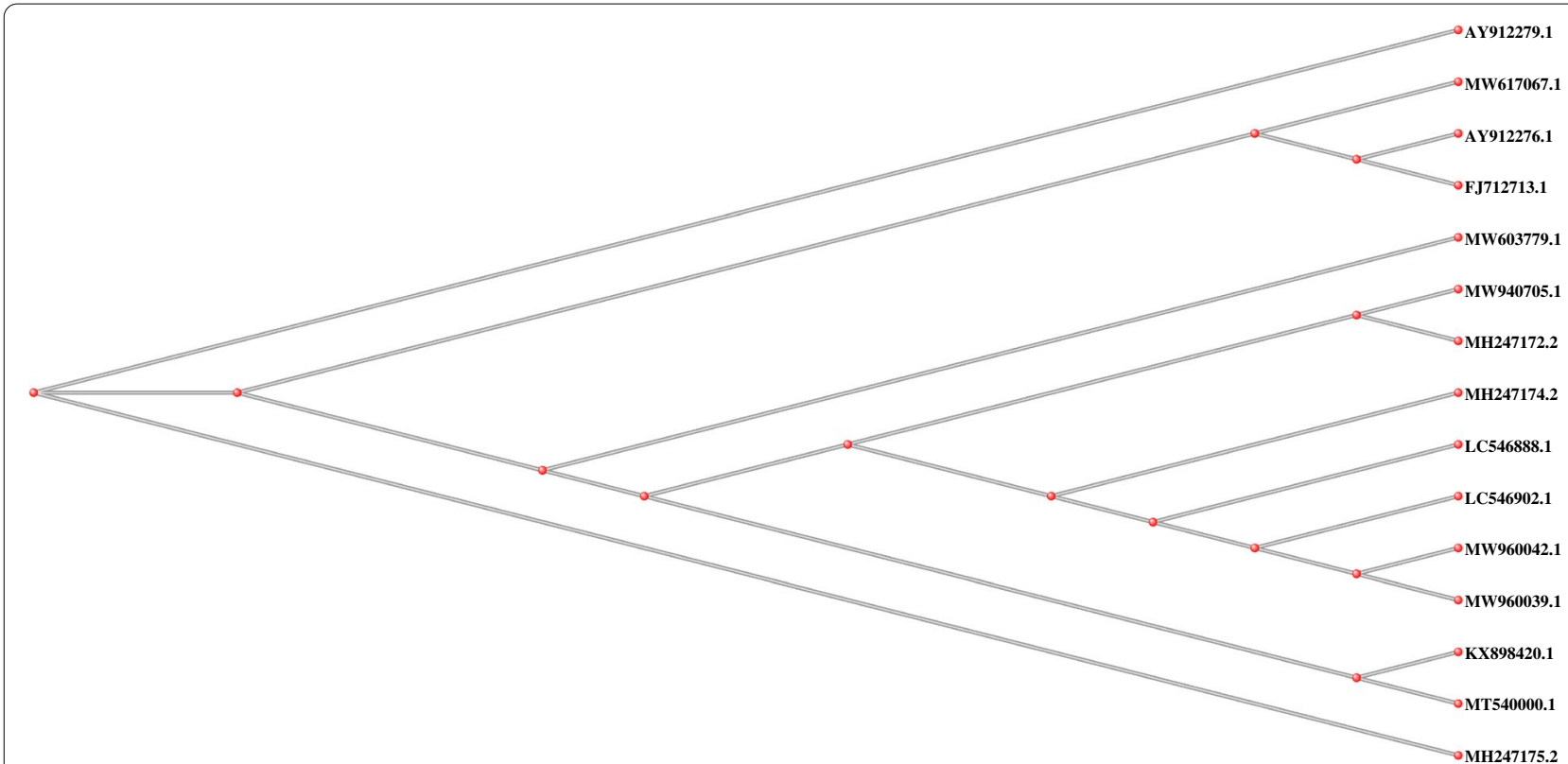

Fig. 3 Phylogenetic relationships between Taif_camel T. evansi (ITS1) MW960042, and MW960039 (using Kin primers), and MW940705 (using ITS primers) with other reference sequences of T. evansi from NCBI GenBank. Trypanosoma GenBank sequences were shown by their accession numbers, country, and host

ILO (488 bp) primers and were sequenced. It is hard to sequence the PCR product of IR primers $(1.1 \mathrm{kbp})$ because it contains other non-specific bands.

Selected sequences were deposited in Genbank and have assigned different accession numbers: MW940705 for ITS1 (one sample using ITS primers), MW960042, and MW960039 for ITS1 (two samples using Kin primers), and RoTat 1.2 VSG (two samples using ILO primers, their sequences are present as supplementary files, unpublished yet) regions, respectively. MW940705, MW960042, MW960039, and VSG were blasted with various related Trypanosoma spp., especially for T. evansi in camels' blood sequences from other different countries (e.g., Kenya, Sudan, Somalia, China, Iran, Egypt, etc.). Phylogenetic trees were constructed from these sequences, as shown in Figs. 3 and 4.

Alignment of MW960042 with MW960039 showed identity with 97\%. Likewise, MW960042 showed 98\% alignment identity with T. evansi LC546902.1 (Philippines), MW617067 (Egypt), FJ712713 (China), AY912276 (Thailand), MT540000 (South Algeria), MH247175 (Kenya), and MH247174 (Kenya).

MW940705 (ITS1 region using ITS primers) showed $100 \%$ alignment identity with $T$. evansi ITS1 MT225591.1 (from India), MH247175.2 (Kenya), MH247174.2 (Kenya), MH247172.2 (Kenya), and LC546888.1 (Philippines), 99.77\% alignment with KX898420.1 (from Iran), MW603779.1 (Egypt),
AY912279 (Thailand), and MT540000 (Algeria). Figure 3 shows MW960042, MW960039, and MW940705 molecular relationship with other most related ITS1 T. evansi from different countries in various hosts as a slanted cladogram.

However, RoTat 1.2 VSG gene sequence of Taif_camel blood samples revealed $100 \%$ alignment identity with T. evansi VSG MK867833.1 (from Kenya), JX134605.1 (India), and KU589274.1 (India), 99\% with JX888091 (Egypt), and 98\% with LC493167 (Sudan) according to NCBI BLAST. Sequence relationship with other most related neighbored sequences was constructed in rectangular cladogram as shown in Fig. 4.

\section{Discussion}

In the present study, we have evaluated trypanosomosis, especially T. evansi, prevalence in camels $(n=102)$ found in Taif governorate in Makkah province of KSA. It is easy to inventory the number of camels in the present study region because most camels were officially numbered in KSA according to the camel's electronic numbering project according to MEWA. It was not easy to find any Trypanosoma spp. in the blood smears of camels. Accordingly, for a more specific and sensitive microscopic parasitic diagnosis, we have used Giemsa-stained buffy coat smear, rather than using the whole blood method, which is used as well for Haemoproteus, Leucocytozoon, Plasmodium, filarioid helminths, Trypanosoma, and Lankesterella 


\section{(A)}

1 tgccgggcac tgcttaggag cgcgcagtta accttggcga tttcgccccc gctagcactc

61 ctcactgatt aagttggcaa cagcaagttt tgtgtgggca aagccgacgg cacaaatgcc

121 gacggtaaca acgaaatcga cgcgctaggg tgcggcgaag ccaactatga cacctcggcc

181 ccaggagaca gctacctaga gggcgacata agcgccgatg gcttcacaaa actaacagcc

241 gttgcagcgg gcaatggaca tgtaggaagc aacacctgcg gggtgtttaa agcaataacc

301 ggcaacgacg gcgaggccgg cgggatcaaa atcgcgacca gcaacatcaa ggtgcacctc

361 gcacacggcc taatcgaagg caaagttgac gaccagccag aacgagcaga attttccaat

421 aatttcggac aaggaaaagc acacacaact gattaaggca gc

(B)

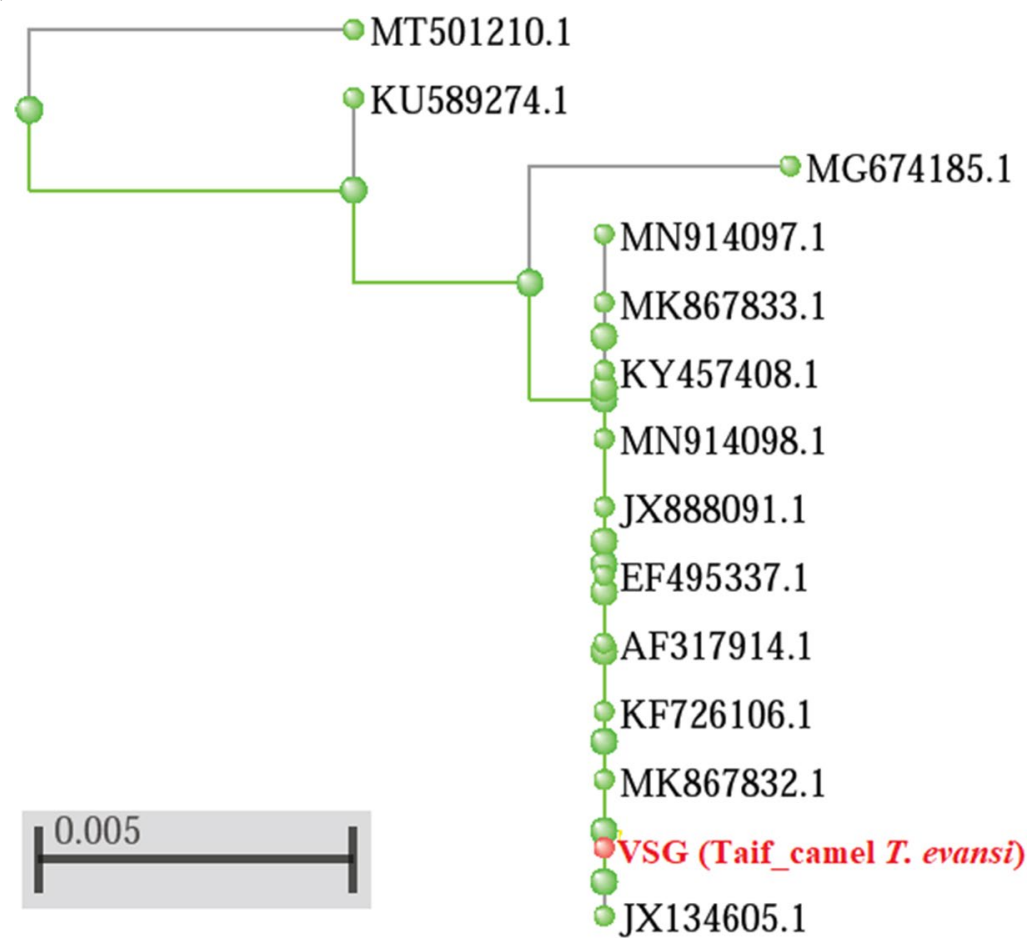

Fig. 4 FASTA sequence of Rotat 1.2 VSG region using ILO primers (A). Its relationship with other reference sequences of T. evansi from NCBI GenBank using phylogenetic tree (B). Trypanosoma GenBank sequences were shown by their names, host names (if present in Genbank), and accession numbers. Bar scale represents 0.005 nucleotide substitution per site

parasites examination [15]. Unfortunately, only two samples, $2 \%$ ( 1 male and one female), have positive results of $T$. evansi infection, and most detected parasites are deformed.

A high prevalence of Trypanosoma spp. (15.7\%) in camels of Taif governorate was reported using PCR, where prevalence among females was significantly higher than that of males (16.7 and $13.9 \%$, respectively). Also, infection caused by $T$. evansi was significantly higher than caused by $T$. vivax (9.8 and $2.9 \%$, respectively). However, prevalence of mixed infection caused by $T$. evansi, T. vivax, and T. congolense together was $2.9 \%$. Low parasitemia, typical for the chronic infection phase, explains the difference of positive results between parasitological and molecular assessment [16]. Further studies have revealed that $T$. evansi is the first leading cause of 
trypanosomosis in camels, followed by $T$. vivax, $T$. congolense, T. brucei, and T. simiae [17]. T. evansi affects many wild and domestic mammals in South America, Asia, and Africa. Globally, T. evansi has its highest prevalence rate in camels than other animal hosts such as horses, dogs, buffaloes, and cattle. Nearly all biting flies could transmit this species as mechanical vectors; therefore, they have potentially unlimited geographical reach [18].

In our peer knowledge, it is the first time to report the prevalence of trypanosomosis in Taif governorate of Makkah province. The present study showed a lower prevalence rate of Trypanosoma spp. (15.7\%), especially T. evansi $(9.8 \%)$, in this region than other regions of Saudi Arabia that have been previously studied. In which, Metwally et al. [12] reported a high prevalence rate of $T$. evansi in Al-Qassim (46\%) and Riyadh (39.5\%) provinces according to molecular evaluation targeting ITS1 gene. We have reported a significantly high prevalence according to sex in females than males, which is consistent with Metwally et al. [12] and inconsistent with other studies in Saudi Arabia and Iraq $[13,19]$. They suggested that the high infection rate in female camels may be returned to low management, traveling through a high vector burden area, and favoritism by biting insects [20]. Considering the number of females included in the present study is more than the number of males because males were slaughtered than females, that gives a chance to spread infection within females.

On the other hand, Al-Afaleq et al. [10] have reported a low prevalence of patent trypanosomosis from the western to the southern regions of KSA (ranges from $0.6-2 \%$ ) according to buffy coat parasitological examination. However, the prevalence rate increased based on serological evaluation by using CATT/T. evansi (39.4\%). Trypanosoma prevalence varied from region to other in KSA and was consistent with other studies in different countries. In Iran, the prevalence rate of $T$. evansi infection has been reported in dromedary camels varied between zero to $19.47 \%$ in various regions [21].

The lower prevalence rate of trypanosomosis, especially T. evansi, in camels of Taif governorate than others in KSA could be returned to various factors. According to the ministerial recommendation, a periodic follow-up examination of camels and wide use of anti-trypanosomal drugs of those reared camels could be the main factor. Anti-trypanosomal drugs have been approved and used in Saudi Arabia, such as Trypomidium-Samorin (isometamedium cholride, Merial), Triquin (quinapyramine, Wock-herde), and Cymelarsan (melarsomine, Merial) [22], that have shown their efficiency in KSA and other neighboring countries, such as the United Arab Emirates [23]. The change of the usage of trypanocides frequency might have a role in prevalence diversity in different regions of KSA [9]. In addition, the abundance of pathogen vectors such as ticks was affected by altitude, temperature, humidity, and saturation deficit. Therefore, high altitude region of Taif and moderate climate could have a role in the low abundance of ticks as previously referred [24]. Gilbert [24] suggested that tick abundance would be higher at lower altitudes, warmer climates that could have potential pathogen prevalence implications.

We have targeted ITS (using IR primers), especially ITS1 (using ITS and Kin primers), and VSG (using ILO primers) regions for molecular determination of T. evansi because they are reliable detection targets [25-27] and are used for delineation of species and phylogenetic relations of Trypanosoma spp. [28, 29]. Isolates of ITS1 and VSG have shown phylogenic relationships with other isolates of T. evansi in different hosts of the Philippines, Egypt, China, Thailand, Kenya, Iran, Sudan, and other countries, as reported in Metwally et al. [12]. However, sequencing more isolates for phylogenic analysis could be useful for the relationship assessment of $T$. evansi in the blood of camels found in Taif governorate, Makkah province, KSA. Finally, there is a need to establish several control policies to decrease trypanosomosis in KSA. Camels' vaccination, control of ticks and pathogen-borne vectors, consistent examination, and import from authorized countries that their animals were free from any pathogens could help control infection rates.

\section{Conclusions}

Results report a considerable prevalence rate of trypanosomosis, especially T. evansi, in the blood of camels reared in the high-altitude region, Taif governorate, of Makkah province in KSA using parasitological and molecular evaluation. However, this prevalence rate is lower than different other governorates in KSA. This reflects health care awareness towards reared camels, follow-up examinations, and medical treatment, if needed, according to ministerial recommendations. In addition, there is a need to establish measures and stringent control policies to help prevent the parasite spread. We also recommend updating the disease prevalence data throughout the whole kingdom that could share in changing the infection situation. In addition, it is necessary to expand phylogenetic analyses for $T$. evansi identification with other more taxa with other molecular markers.

\section{Methods}

\section{Study area}

Taif governorate is a high-altitude region (about $1.87 \mathrm{~m}$ above sea level) in Makkah province of KSA with a special climate due to its geographical position and altitude. According to Köppen and Geiger, the Taif climate 


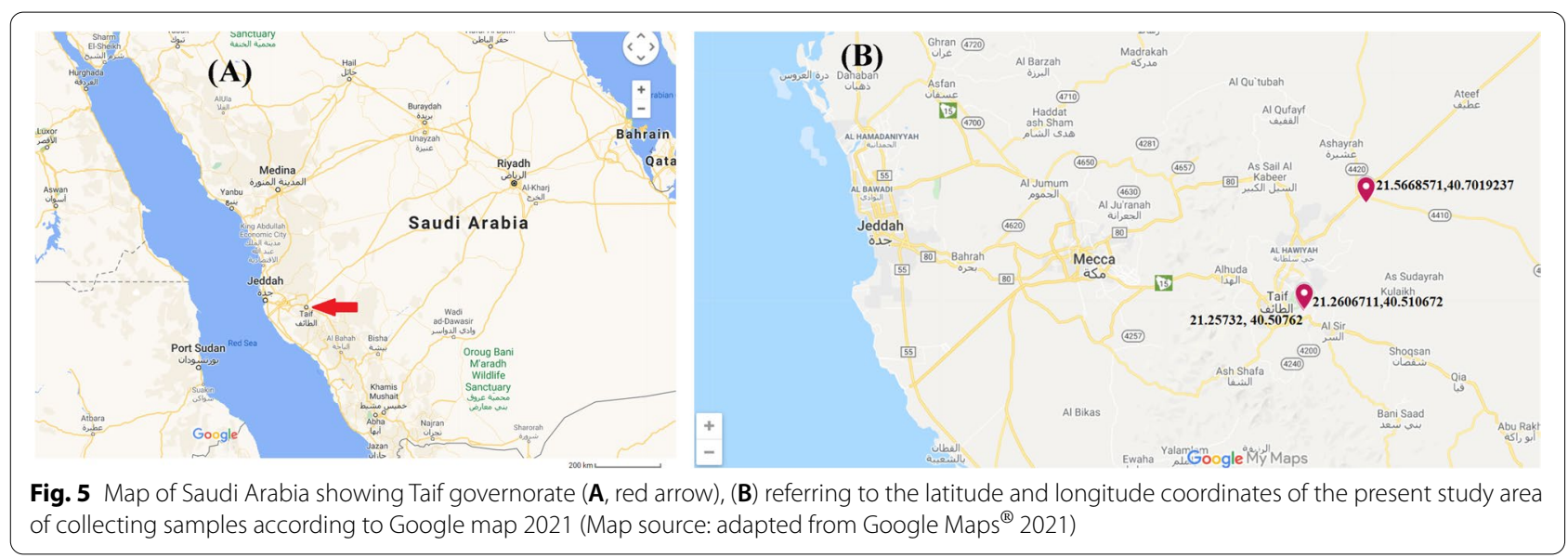

is classified as a hot desert climate (BWh) [30]. We have selected the most popular areas in Taif that found camels grazed in to collect our data/samples. Most of the camels in Taif governorate were found grazing in three different regions with latitude and longitude coordinates $21^{\circ} 5,668,571 \mathrm{~N} \quad 40^{\circ} 7019237 \mathrm{E}, \quad 21^{\circ} 25,732 \mathrm{~N} \quad 40^{\circ} 50762 \mathrm{E}$, and $21^{\circ} 2,606,711 \mathrm{~N} 40^{\circ} 510672 \mathrm{E}$, respectively (Fig. 5). It is easy for us to locate and collect their data because most camels were officially numbered according to the camel's electronic numbering project established in KSA as an obligatory measure since 2017 according to the Ministry of Environment, Water, and Agriculture (MEWA).

\section{Animals' data and sample collection}

According to the ministerial recommendation, camels (Camelus dromedarius) were subjected to periodic examination by veterinarians. Blood samples were collected from their side to ensure that animals were free from diseases. Data about camels such as age, gender, other different data, and $2 \mathrm{ml}$ of collected blood samples (from ear veins) in EDTA tubes were introduced from veterinarians as per their periodic examination. Data and blood samples were collected from the period December 2020 to February 2021. At the time of blood collection, camels were clinically healthy. A total of 102 samples, 66 females (age ranges from 3-12 years) and 36 males (age ranges from 1-7years), were evaluated.

\section{Parasitological evaluation}

Blood and buffy smears were done for all samples, stained with $10 \%$ Giemsa, and examined under a light microscope for Trypanosoma spp. diagnosis [31].

\section{DNA extraction}

DNA was extracted manually by salting out. First, a $0.5 \mathrm{ml}$ blood sample was mixed with the same volume of low salt buffer TKM1 (100 mM Tris-HC1, pH 7.4, 250 mM sucrose, $10 \mathrm{mM}$ EDTA) and incubated at room temperature until complete blood cells' lysis. Next, the mixture was centrifuged ( $4000 \mathrm{rpm}, 10 \mathrm{mins}$ ), and then $480 \mu \mathrm{l}$ of high salt buffer TKM2 (Tris $\mathrm{HCl} 10 \mathrm{mM} \mathrm{pH} 7.6,10 \mathrm{mM} \mathrm{KCl}, 10 \mathrm{mM}$ $\mathrm{MgCl}_{2}, 0.4 \mathrm{M} \mathrm{NaCl}$, and $2 \mathrm{mM}$ EDTA), $75 \mu \mathrm{l} 10 \% \mathrm{SDS}$, and $10 \mu \mathrm{l}$ proteinase $\mathrm{k}$ enzyme $(10 \mathrm{mg} / \mathrm{ml})$ were added to the pellet and incubated at $55^{\circ} \mathrm{C}$ for 30 mins. Protein was precipitated by the aid of $6 \mathrm{M} \mathrm{NaCl}$, centrifuged $(11,500 \mathrm{rpm}$, 20 mins), and then supernatant was transferred to new eppendorf for DNA precipitation by cold ethanol addition. Next, the DNA pellet was collected by centrifugation

Table 2 Primers and target genes of Trypanosoma spp. investigated [33-36]

\begin{tabular}{|c|c|c|c|}
\hline Primers $\left(5^{\prime}-3^{\prime}\right)$ & Target gene & Product size (bp) & Cycling conditions (same for all primers) \\
\hline For-Kin: GCGTTCAAAGATTGGGCAAT & ITS1 & T. evansi (540 bp), T. vivax (300 bp) & \multirow{8}{*}{$\begin{array}{l}94^{\circ} \mathrm{C}-3 \min \\
94^{\circ} \mathrm{C}-1 \min \\
58^{\circ} \mathrm{C}-1 \min (\times 4) \\
72^{\circ} \mathrm{C}-1 \min \\
94^{\circ} \mathrm{C}-1 \min \\
56^{\circ} \mathrm{C}-1 \min (\times 8) \\
72^{\circ} \mathrm{C}-1 \min \\
94^{\circ} \mathrm{C}-1 \min \\
54^{\circ} \mathrm{C}-1 \min (\times 23) \\
72^{\circ} \mathrm{C}-1 \min \\
72^{\circ} \mathrm{C}-5 \min [37]\end{array}$} \\
\hline Rev-Kin: CGCCCGAAAGTTCACC & & & \\
\hline For-ILO: GCCACCACGGCGAAAGAC & Rotat 1.2 VSG & T. evansi (488 bp) & \\
\hline Rev-ILO: TAATCAGTGTGGTGTGC & & & \\
\hline For-IR: GCTGTAGGTGAACTTGCAGCAGCTGGATCATT & ITS & T.evansi (1.1 kbp) & \\
\hline Rev-IR: GCGGGTAGTCCTGCCAAACACTCAGGTCTG & & & \\
\hline For-ITS1: CCGGAAGTTCACCGATATTG & ITS1 & T. evansi (480 bp), T. vivax (250 bp), & \\
\hline Rev-ITS1:TTGCTGCGTTCTTCAACGAA & & T. congolense (620 bp). & \\
\hline
\end{tabular}


(10,000 rpm, 10 mins), washed, dried, and finally dissolved in $100 \mu$ l autoclaved Milli-Q water [32].

\section{PCR amplification}

The internal transcribed spacer (ITS) region (consists of ITS1+5.8S+ ITS2 rDNA), ITS- 1 , and RoTat 1.2 variable surface glycoprotein (VSG) regions of T. evansi were targeted by different primers as mentioned in Table 2 . For-Kin, Rev-Kin; For-ITS1, Rev-ITS1; and For-IR, RevIR primers were used for ITS1, and ITS different regions amplification, while For-ILO and Rev-ILO were used for RoTat 1.2 (VSG) region amplification as previously cited [33-36].

PCR amplification was done in a total reaction volume of $20 \mu \mathrm{l}: 7 \mu \mathrm{l} \mathrm{H} \mathrm{H}_{2} \mathrm{O}, 1 \mu \mathrm{l}$ (20 pmole) of each forward and reverse primers, $1 \mu \mathrm{l}$ extracted DNA, and finally $10 \mu \mathrm{l}$ of $2 \times$ master mix. Touchdown PCR reaction was setup over 35 cycles as shown in Table 2 [37]. PCR products of all samples were loaded and separated at $2 \%$ ethidium bromide-stained agarose gel in a TBE buffer (1X) for about $45 \mathrm{~min}(100 \mathrm{v})$, visualized, and then photographed by a gel documentation system. The size of PCR products was determined visually by comparing them with a known low molecular weight marker (50-1500 bp).

\section{Sequencing and phylogenetic assessment}

Positive PCR products of T. evansi were selected and subjected to sequencing using an ABI Prism 3730 Genetic Analyzer automated sequencer. Sequences of different amplicons of ITS1 and RoTat 1.2 (VSG) regions were submitted in Genbank with the help of NCBI Genome Workbench software (version 3.6.0, built on 03/01/2021) to have accession numbers. Sequences of different regions of ITS, ITS1, and RoTat 1.2 (VSG) were aligned with various sequences in Genbank, estimated phylogenetically, and finally viewed as slanted/rectangular cladogram in the phylogenic Tree View by using NCBI Genome workbench and online NCBI BLAST [38].

\section{Statistical analysis}

Statistical analysis was conducted to differentiate between different groups by using One-way ANOVA using GraphPad software (GraphPad ${ }^{\circledR}$ 2017, San Diego, CA, USA). ${ }^{* * * *}$ indicates $P \leq 0.001$, **: indicates $P \leq 0.01$, * indicates $P \leq 0.05$ and ns (non-significant) means $P>0.05$.

\section{Abbreviations}

BWh: Hot deserts climate; ITS: Internal transcribed spacer; KSA: Kingdom of Saudi Arabia; MEWA: Ministry of Environment, Water, and Agriculture; T. evansi: Trypanosoma evansi; VSG: Variable surface glycoprotein.

\section{Supplementary Information}

The online version contains supplementary material available at https://doi. org/10.1186/s12917-022-03148-0.

Additional file 1.

Additional file 2.

Acknowledgments

This work was supported by Taif University Researchers Supporting Project number (TURSP-2020/299), Taif University, Taif, Saudi Arabia. The authors would like to thank the Ministry of Agriculture and Water in Taif governorate for facilitating data and sample collections. Special thanks are due to Dr. Ehab Tantawy for editing the manuscript.

\section{Authors' contributions}

$\mathrm{JM}$, and $\mathrm{NH}$ participated in the design of the study. JM collected samples and performed parasitological assay. JM and NH carried out molecular evaluation. $\mathrm{NH}$ performed data analysis and wrote the article draft. JM, and $\mathrm{NH}$ read and approved the final manuscript.

\section{Funding}

This work was supported by Taif University Researchers Supporting Project number (TURSP-2020/299), Taif University, Taif, Saudi Arabia.

\section{Availability of data and materials}

The datasets analysed during the current study are available in Genbank with accession numbers MW940705, MW960042, and MW960039 for ITS1 region. VSG sequences are available as PDF supplementary files.

\section{Declarations}

\section{Ethics approval and consent to participate}

Data and samples were collected from veterinarians as per their periodic examination according to the ministerial recommendation. We have a permission letter from the Ministry of Environment, Water and Agriculture (KSA) to collect cattle samples from different locations in Taif for our research study with the number 106082/1074/1442, date 21-02-1442H. Sample's collection and all experimental procedures were performed following a national ethical requirement. National Committee of Bioethics (NCBE) at King Abdulaziz City for Science and Technology (KACST) with number: 10023117, valid till 01 October 2023. Consent to participate: Not applicable.

\section{Consent for publication}

Not applicable.

\section{Competing interests}

The authors declare that they have no competing interests.

Received: 26 May 2021 Accepted: 7 January 2022

Published online: 18 January 2022

References

1. FAO-statistics. Available from: http://faostat.fao.org. 2019.

2. Gaili ESE, Al-Eknah M, Mansour H. Systems of camel management in Saudi Arabia. Arab J Agric Res. 2000;116:148-56.

3. Faye B. The camel, new challenges for a sustainable development. Trop Anim Health Prod. 2016;48:689-92.

4. Pathak K. Evaluation of various diagnostic techniques for Trypanosoma evansi infection in naturally infected animals. Vet Parasitol. 1997;69:49-54.

5. Alanazi AD, Puschendorf R, Salim B, Alyousif MS, Alanazi IO, Al-Shehri HR. Molecular detection of equine trypanosomosis in the Riyadh Province of Saudi Arabia. J Vet Diagn Investig. 2018;30(6):942-5.

6. Mossaad E, Salim B, Suganuma K, Musinguzi P, Hassan MA, Elamin EA, et al. Trypanosoma vivax is the second leading cause of camel trypanosomosis in Sudan after Trypanosoma evansi. Parasit Vectors. 2017;10(1):176. 
7. Joshi PP, Shegokar VR, Powar RM, Herder S, Katti R, Salkar HR, et al. Human trypanosomiasis caused by Trypanosoma evansi in India: the first case report. Am J Trop Med Hyg. 2005;73:491-5.

8. Van Vinh CN, Buu Chau L, Desquesnes M, Herder S, Phu Huong Lan N, Campbell Jl, et al. A clinical and epidemiological investigation of the first reported human infection with the zoonotic parasite Trypanosoma evansi in Southeast Asia. Clin Infect Dis. 2016;62:1002-8.

9. Desquesnes M, Dargantes A, Lai DH, Lun ZR, Holzmuller P, Jittapalapong S. Trypanosoma evansi and surra: a review and perspectives on transmission, epidemiology and control, impact, and zoonotic aspects. Biomed Res Int. 2013;2013:321237.

10. Al-Afaleq Al, Elamin EA, Fatani A, Homeida AG. Epidemiological aspects of camel trypanosomosis in Saudi Arabia. J Camel Pract Res. 2015;22:231-4.

11. Luckins AG, Dwinger RH. Non-tsetse-transmitted animal trypanosomiasis. In: Maudlin I, et al., editors. The Trypanosomiases. Oxfordshire: CABI; 2004. p. 269-81.

12. Metwally DM, Al-Turaiki IM, Altwaijry N, Alghamdi SQ, Alanazi AD. Molecular Identification of Trypanosoma evansi Isolated from Arabian Camels (Camelus dromedarius) in Riyadh and Al-Qassim, Saudi Arabia. Animals. 2021;11:1149.

13. Hussein HS, Al-Asgah NA, Al-Khalifa MS, Diab FM. The blood parasites of indigenous livestock in Saudi Arabia. Arab Gulf J Sci Res. 1991;9:143-60.

14. Al-Khalifa MS, Hussein HS, Diab FM, Khalil GM. Blood parasites of livestock in certain Regions in Saudi Arabia. Saudi J Biol Sci. 2009;16:63-7.

15. Chagas CRF, Binkienè R, Ilgūnas M, lezhova T, Valkiūnas $G$. The buffy coat method: a tool for detection of blood parasites without staining procedures. Parasit Vectors. 2020;13(1):104

16. Shahzad W, Munir R, Khan MS, Ahmad MD, ljaz M, Ahmad A, et al. Prevalence and molecular diagnosis of Trypanosoma evansi in Nili-Ravi buffalo (Bubalus bubalis) in different districts of Punjab (Pakistan). Trop Anim Health Prod. 2010;42:1597-9.

17. Alharbi MEM, Mohamed YO, Elshafie El, Alharbi YJA, Al-Mekhlafi HM. Molecular detection of Trypanosoma evansi in camels (Camelus dromedarius) in southwestern Saudi Arabia. Thai J Vet Med. 2019;49(1):93-100.

18. Aregawi WG, Agga GE, Abdi RD, Büscher P. Systematic review and meta-analysis on the global distribution, host range, and prevalence of Trypanosoma evansi. Parasit Vectors. 2019;12:67. https://doi.org/10.1186/ s13071-019-3311-4.

19. Al-Amery AM, Faraj AA, Majeed SA. Detection of haemoprotozoa in camels in Al Najaf province. Iraq Int J Adv Biol Res. 2017;7:238-41.

20. Tehseen S, Jahan N, Desquesnes M, Shahzad MI, Qamar MF. Field investigation of Trypanosoma evansi and comparative analysis of diagnostic tests in horses from Bahawalpur, Pakistan. Turk J Vet Anim Sci. 2017;41:288-93.

21. Sazmand A, Joachim A. Parasitic diseases of camels in Iran (1931-2017) - a literature review. Maladies parasitaires des dromadaires en Iran (1931-2017) - Revue de la littérature. Parasite. 2017;24:21. https://doi.org/ 10.1051/parasite/2017024.

22. Al-Dughym AM, Al-Afaleq Al, Homeida AM. Review of adverse effects of drugs in camels. La Revue de Elev de Medecine Veterinaire des Pays Tropicals. 1998;51:81-6.

23. Central Veterinary Research Laboratory. UAE, Annual Report; 1999.

24. Gilbert L. Altitudinal patterns of tick and host abundance: a potential role for climate change in regulating tick-borne diseases? Oecologia. 2010;162(1):217-25. https://doi.org/10.1007/s00442-009-1430-x.

25. Sengupta PP, Balumahendiran M, Suryanarayana W, Raghavendra AG, Shome BR, Gajendragad MR, et al. PCR-based diagnosis of surra-targeting VSG gene: Experimental studies in small laboratory rodents and buffalo. Vet Parasitol. 2010;171:22-31.

26. Salim B, Bakheit MA, Kamau J, Nakamura I, Sugimoto C. Molecular epidemiology of camel trypanosomiasis based on ITS-1 rDNA and RoTat 1.2 VSG gene in Sudan. Parasit Vectors. 2011;4:1-5.

27. Elwathig M, Faye B, Thevenon S, Ravel S, Bossard G. Epidemiological surveys of camel trypanosomosis in Al-Jouf, Saudi Arabia based on PCR and ELISA. Emir J Food Agric. 2016;28:212-6.

28. Amer S, Ryu O, Tada C, Fukuda Y, Inoue N, Nakai Y. Molecular identification and phylogenetic analysis of Trypanosoma evansi from dromedary camels (Camelus dromedarius) in Egypt, a pilot study. Acta Trop. 2011;117:39-46.

29. Khuchareontaworn S, Singhaphan P, Viseshakul N, Chansiri K. Genetic diversity of Trypanosoma evansi in buffalo based on internal transcribed spacer (ITS) regions. J Vet Med Sci. 2007;69:487-93.
30. Climate At Taif (Saudi Arabia). Taif climate: Average Temperature, weather by month, At Taif weather averages - Climate-Data.org. [online] En.climate-data.org. Available at: https://en.climate-data.org/asia/saudiarabia/makkah-region/at-taif-5872. [Accessed 11 Aug 2021].

31. Schalm OW. Veterinary hematology. 2nd ed. Philadelphia: Lea \& Febiger; 1971.

32. Ahmad S, Ghosh A, Nair DL, Seshadri M. Simultaneous extraction of nuclear and mitochondrial DNA from human blood. Genes Genet Syst. 2007;82:429-32.

33. Desquesnes M, McLaughlin G, Zoungrana A, Dávila AM. Detection and identification of Trypanosoma of African livestock through a single PCR based on internal transcribed spacer 1 of rDNA. Int J Parasitol. 2001:31:610-4.

34. Urakawa T, Verloo D, Moens L, Büscher P, Majiwa PA. Trypanosoma evansi: cloning and expression in Spodoptera fugiperda insect cells of the diagnostic antigen RoTat1. 2. Exp Parasitol. 2001;99:181-9.

35. Da Silva FM, Noyes H, Campaner M, Junqueira AC, Coura JR, Anez N, et al. Phylogeny, taxonomy and grouping of Trypanosoma rangeli isolates from man, triatomines and sylvatic mammals from widespread geographical origin based on SSU and ITS ribosomal sequences. Parasitology. 2004;129:549-61.

36. Njiru ZK, Constantine CC, Guya S, Crowther J, Kiragu JM, Thompson RCA, et al. The use of ITS1 rDNA PCR in detecting pathogenic African trypanosomes. Parasitol Res. 2005;95(3):186-92.

37. Tran T, Napier G, Rowan T, Cordel C, Labuschagne M, Delespaux V, et al. Development and evaluation of an ITS1 "Touchdown" PCR for assessment of drug efficacy against animal African trypanosomosis. Vet Parasitol. 2014;202:3-4.

38. Kuznetsov A, Bollin CJ. NCBI Genome Workbench: Desktop Software for Comparative Genomics, Visualization, and GenBank Data Submission. Methods Mol Biol. 2021;2231:261-95.

\section{Publisher's Note}

Springer Nature remains neutral with regard to jurisdictional claims in published maps and institutional affiliations.

Ready to submit your research? Choose BMC and benefit from:

- fast, convenient online submission

- thorough peer review by experienced researchers in your field

- rapid publication on acceptance

- support for research data, including large and complex data types

- gold Open Access which fosters wider collaboration and increased citations

- maximum visibility for your research: over $100 \mathrm{M}$ website views per year

At BMC, research is always in progress.

Learn more biomedcentral.com/submissions 